
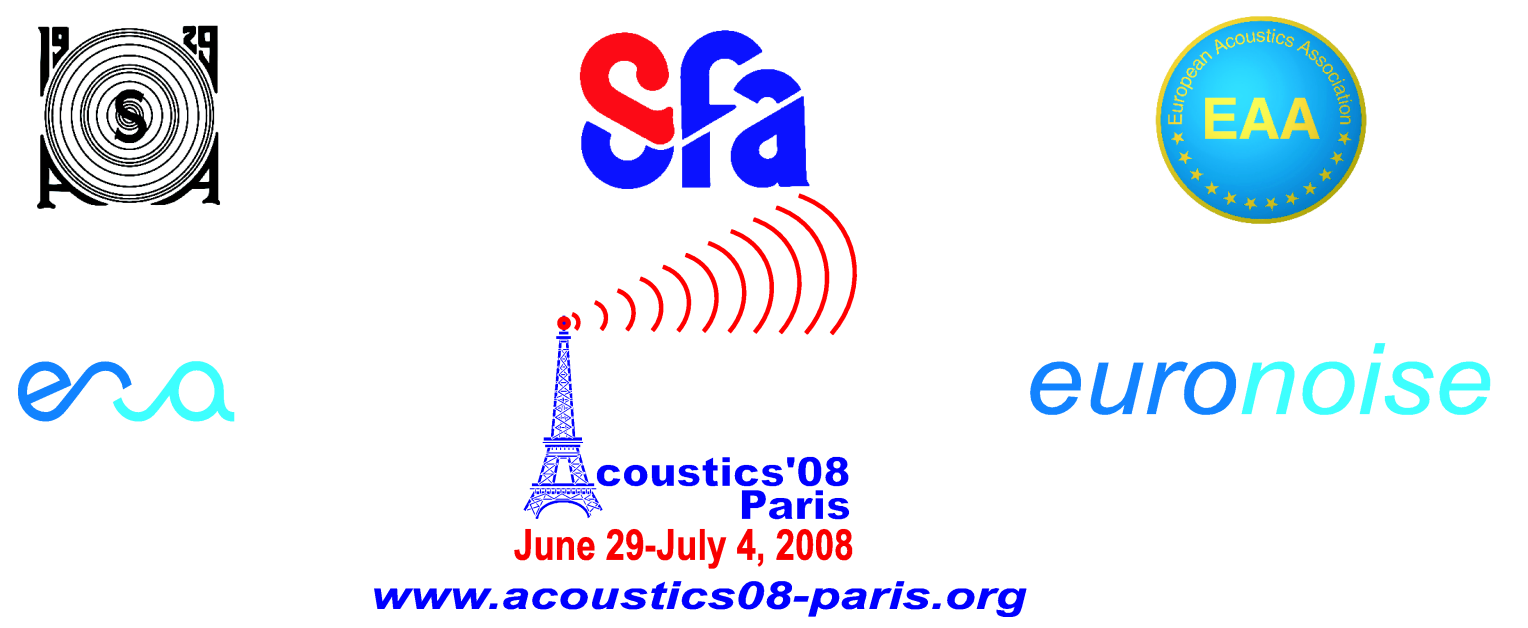

\title{
Wind farm aural and visual impact in the Netherlands
}

F. Van Den Berg ${ }^{\mathrm{a}}$, E. Pedersen ${ }^{\mathrm{b}}$, R. Bakker ${ }^{\mathrm{c}}$ and J. Bouma ${ }^{\mathrm{c}}$

${ }^{a}$ University of Groningen - Science \& Society Group, Nijenborgh 4, 9747AG Groningen, Netherlands

${ }^{\mathrm{b}}$ Occupational and Environmental Medicine, Göteborg University, PO Box 100, SE-405 30 Göteborg, Sweden

${ }^{\mathrm{c}}$ Northern Centre for Healthcare Research, University Medical Centre Groningen, PO Box 30001, 9700 RB Groningen, Netherlands fvdberg@ggd.amsterdam.nl 
The WINDFARMperception project, carried out in 2007/08 in the Netherlands, aimed to explore the impact of wind farms on people living close to wind farms. The study sample was selected in three types of area (countryside, countryside with major road, built up area) by means of a Geographic Information System (GIS). Each selected address was within $2.5 \mathrm{~km}$ of a wind turbine of at least $500 \mathrm{~kW}$ electric power and a similar turbine within $500 \mathrm{~m}$ of the first. Aural impact was calculated according to three different sound propagation models: the international ISO-9613 standard, the model legally required in the Netherlands, and a simplified model as in the New Zealand Standard NZS-6808. Visual impact was quantified in two ways: the vertical angle determined by the height of the apparently tallest turbine, and the solid angle determined by all turbines where each turbine was replaced by a vertical rectangle just enclosing the turbine. Immission sound levels from the wind farms at 1948 receiver locations varied from 21 to $54 \mathrm{~dB}(\mathrm{~A})$, relative size from $0.01 \%$ to $30 \%$ of the total field of view. Results show that all impact measures are highly correlated with distance to the nearest wind turbine.

\section{Introduction}

To investigate the visual and aural effects of wind farms on nearby residents the project 'WINDFARMperception' was started. The purpose of the survey is to yield information on the impact of a wind farm on local residents, with an emphasis on visual and noise impact and the possible interaction between both. The result is expected to help in understanding to what degree a wind farm affects residents and what characteristics determine the impact. Such results could help in finding mitigation measures that may be effective in reducing local impact.

This paper describes the procedures to select a study group of Dutch residents and the calculation of the visual and aural dose. In a second paper the survey and results will be described [1].

\section{Selection of study group}

At the start of the project a list of wind turbines was available but no sound power data. To be able to start the study group selection, as a first stage postcodes were selected within $2.5 \mathrm{~km}$ of all modern wind farms and addresses obtained for the selected post codes. In the second stage, when sound immission levels were available, a further selection was made to obtain the names and addresses of the proper study group.

The following criteria were determined to select a study group from the Dutch population:

- $\quad$ five exposure groups: < 30, 30-35, 35-40, 40-45 and > $45 \mathrm{~dB}(\mathrm{~A})$ (immission sound level at residence due to wind farm).

- $\quad$ three environments: quiet rural, rural with a main road, built up area (the first two refer to dispersed residences and small villages, the last one to large villages and towns).

- equal numbers -if possible- of the population in each exposure group.

- in each of the $5 \times 3$ groups preferably 50 respondents or more.

With an expected response rate of at least $33 \%$ we therefore planned a study group size of preferably 2250 individuals.

\subsection{Wind turbine selection}

Locations of all onshore wind turbines in the Netherlands were provided by Wind Service Holland (WSH). A first list gave the status quo on March 1, 2006, a second one the status quo on February 26, 2007. From the difference between both lists changes could be determined that had occurred in the year preceding the survey.

As the project aimed to study perception around modern wind farms, small wind turbines $(<500 \mathrm{~kW})$ and single wind turbines (no other wind turbine within $500 \mathrm{~m}$ ) were excluded. To be able to obtain results for the three different environments, wind turbines on large industrial estates and in 'mixed areas' (residential, business and rural within the same area) were also excluded. This was determined from detailed (1:50 000) topographic maps.

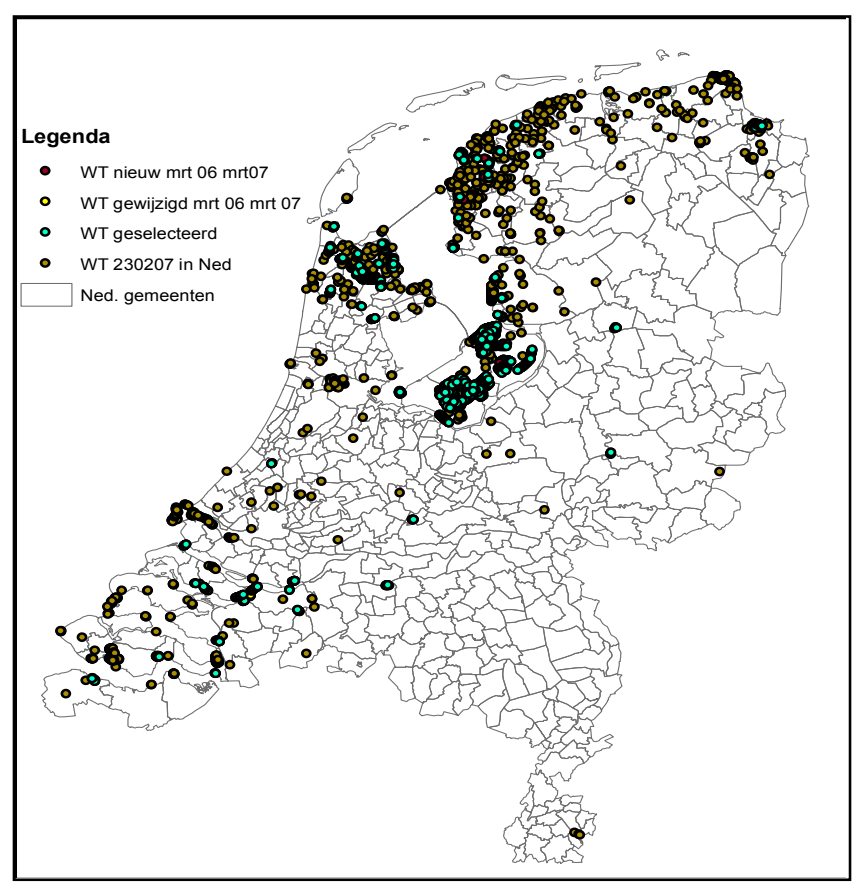

Figure 1: positions of all wind turbines in the Netherlands

As we wanted to rule out short term, transitory effects, residents living near a wind farm completed within one year before the survey (in fact 14 months: completed after March 2006) were excluded, as were situations with changes in the wind farm (replacing and/or and dismantling older turbines) in the 12 months preceding March 2007. 


\subsection{Postcode selection}

With Arcmap 9.2 software postcodes were selected in relation to their distance to the closest wind turbine. From these postcodes a number were not suitable for the purpose of this project. Therefore postcodes in the following areas have been deleted:

- $\quad$ mixed areas, where different area types are close to a selected turbine and it is unclear in which area type a postcode or address should be classified.

- an industrial area type is not chosen in this project, because very few people live within the lower distance ranges and other industrial sources are likely to be present and interfere with the wind farm sound.

- $\quad$ in some cases there were larger villages/small towns in the higher distance ranges of the rural areas. These would increase the study group size of the built up areas, but only in the lower sound level classes where it was expected the study group was already large enough.

Within $2.5 \mathrm{~km}$ from the selected wind turbines we finally had 4570 six-position postcodes. For these postcodes we have requested the Land Registry Office (Kadaster) the related addresses classified as permanent or holiday residences from the Dutch address coordinates file (ACN).

\subsection{Address selection}

The previous step yielded 50073 residential addresses with individual $\mathrm{x}$ and $\mathrm{y}$ coordinates. For all addresses the immission sound level was calculated with a provisional list of wind turbine types (some with estimated sound power levels). The addresses were then classified in $5 \mathrm{~dB}$ sound immission level classes $(<30,30-35,35-40,40-45,>45$ $\mathrm{dB}(\mathrm{A}))$ for each of the three environments. 23160 addresses at sound levels $\leq 25 \mathrm{~dB}(\mathrm{~A})$ were deleted from the sample. In some subgroups there were less than 150 addresses. In most there were more and a random sample from all addresses in that subgroup was used. This resulted in 3727 selected addresses. The address supplier could provide names and telephone numbers for 2056 of the 3727 addresses. From these we used 1948 addresses where a private name was given, not when the name was apparently of a business or organization (the remaining 108 addresses).

\section{Wind turbine sound levels}

The manufacturer and type of all wind turbines in the Netherlands are part of the information supplied by WSH. As of March 2006, there were 1735 wind turbines in the Netherlands. One year later there were 1839 wind turbines, mostly because the number of large turbines $(\mathrm{P}>2 \mathrm{MW})$ had increased. In table 2 these are classified in electric power ranges.

78 different types of wind turbines were present. Most popular are the medium sized Vestas turbines (600 to 900 $\mathrm{kW} ; 291$ turbines) and the small Lagerweij turbines (75 and $80 \mathrm{~kW} ; 241$ turbines)

\begin{tabular}{|c|c|c|c|c|c|}
\hline $\begin{array}{l}\text { sound } \\
\text { class }\end{array}$ & $\begin{array}{c}\text { all addr.s } \\
\text { present }\end{array}$ & $\begin{array}{c}\text { addr.s } \\
\text { selected }\end{array}$ & $\begin{array}{l}\text { addr.s } \\
\text { needed }\end{array}$ & $\begin{array}{c}\text { \% needed/ } \\
\text { selected }\end{array}$ & $\begin{array}{c}\text { addr.s } \\
\text { ordered }\end{array}$ \\
\hline \multicolumn{6}{|c|}{ built up area } \\
\hline$>45$ & 11 & 10 & all & 100 & 10 \\
\hline $40-45$ & 103 & 91 & all & 100 & 91 \\
\hline $35-40$ & 508 & 404 & 150 & 37 & 330 \\
\hline $30-35$ & 2294 & 1785 & 150 & 8 & 330 \\
\hline $25-30$ & 8563 & 6268 & 150 & 2 & 330 \\
\hline$<=25$ & 15632 & 7068 & 0 & & 0 \\
\hline \multicolumn{6}{|c|}{ rural + main road } \\
\hline$>45$ & 124 & 123 & all & 100 & 123 \\
\hline $40-45$ & 302 & 177 & 150 & 85 & 177 \\
\hline $35-40$ & 1545 & 1242 & 150 & 12 & 330 \\
\hline $30-35$ & 4024 & 2478 & 150 & 6 & 330 \\
\hline $25-30$ & 9280 & 5255 & 150 & 3 & 330 \\
\hline$<=25$ & 16835 & 7554 & 0 & & 0 \\
\hline \multicolumn{6}{|l|}{ rural } \\
\hline$>45$ & 151 & 150 & all & 100 & 150 \\
\hline $40-45$ & 358 & 206 & 150 & 73 & 206 \\
\hline $35-40$ & 1151 & 792 & 150 & 19 & 330 \\
\hline $30-35$ & 3713 & 2561 & 150 & 6 & 330 \\
\hline $25-30$ & 9085 & 5371 & 150 & 3 & 330 \\
\hline$<=25$ & 17624 & 8538 & 0 & & 0 \\
\hline all & & 50073 & 2024 & & 3727 \\
\hline
\end{tabular}

Table 1: number of addresses (addr.s) per immission sound level range

\begin{tabular}{|c|c|c|}
\hline $\begin{array}{l}\text { max. electric } \\
\text { power P (MW) }\end{array}$ & $\begin{array}{c}\text { number of turbines } \\
\text { March 1, 2006 }\end{array}$ & $\begin{array}{c}\text { number of turbines } \\
\text { February 23, 2007 }\end{array}$ \\
\hline $\mathrm{P}<0.5$ & 679 & 657 \\
\hline $0.5 \leq \mathrm{P}<1$ & 698 & 704 \\
\hline $1 \leq \mathrm{P}<1.5$ & 83 & 86 \\
\hline $1.5 \leq \mathrm{P}<2$ & 138 & 138 \\
\hline $2 \leq \mathrm{P}<2.5$ & 94 & 157 \\
\hline $2.5 \leq \mathrm{P}$ & 43 & 97 \\
\hline
\end{tabular}

Table 2: number of wind turbines in $0.5 \mathrm{MW}$ classes 


\subsection{Sound power data}

For each type of turbine relevant to this project sound power data had to be obtained, preferably the sound emission level per octave band and the total sound emission level as a function of wind speed. These data were obtained from our archives, the internet and local authorities.

From the spectral data that have been collected the available octave band data, relative to the total sound power level at $8 \pm 1 \mathrm{~m} / \mathrm{s}$ wind speed (depending on data availability), are plotted in figure 2 . This is in standard

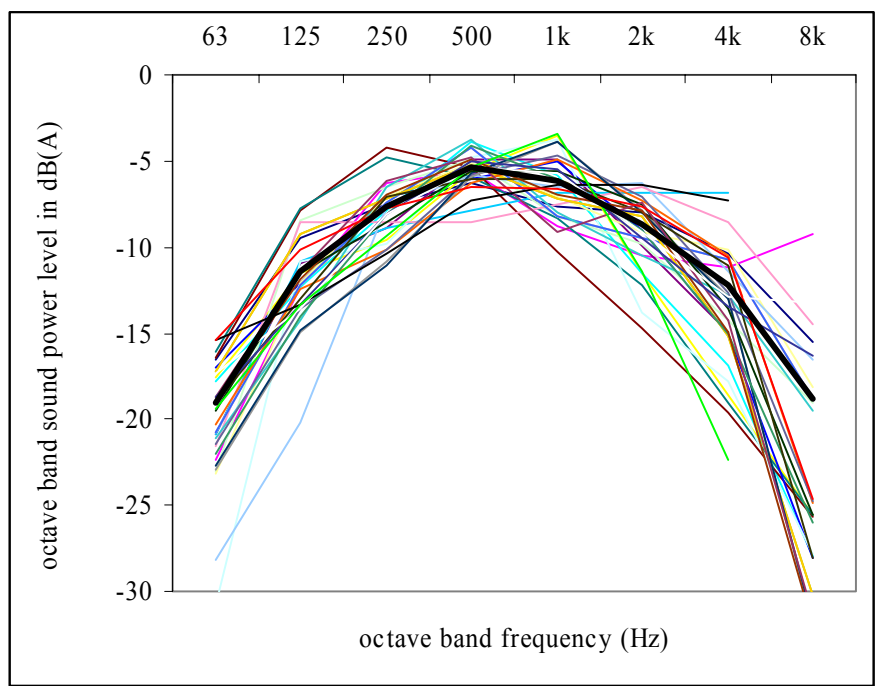

Figure 2: A-weighted octave band sound power levels relative to total A-weighted sound power; bold line is average of all octave band data

conditions according to IEC [2], and with the wind speed at $10 \mathrm{~m}$ height. Also the (logarithmically) averaged values are shown. The figure shows that the spectral form is very similar for all turbines, as Sondergaard has shown for another set of wind turbines [3]. Especially at the dominant levels in the middle frequency range $(500-1000 \mathrm{~Hz})$ all spectral values are in a relatively narrow range.

\subsection{Sound propagation models}

Three sound propagation models have been used:

- the standard Dutch model as described in the 'Manual to measure and calculate industrial noise' [4], further referred to as 'the Dutch model'.

- the model described in ISO-9613.2 [5], representing the international standard for acoustic calculations.

- a simplified model such as used in the New Zealand Standard for Wind Turbine Noise [6]; this model was used by Pedersen and Persson Waye in their first study of wind turbine noise annoyance [7].

\subsection{Sound dose}

For all addresses the immission sound level was calculated from the sound power level at high electric power $(8 \mathrm{~m} / \mathrm{s}$ wind speed at $10 \mathrm{~m}$ in neutral atmosphere), as was done in a similar earlier survey [7]. Also, the sound level at 7 to $8 \mathrm{~m} / \mathrm{s}$ is most dominant for modern wind turbines [8]. If different operational modes were present, the highest (loudest) mode was used. Receiver height was taken as $5 \mathrm{~m}$, ground absorption as $100 \%$. Although addresses were selected within $2.5 \mathrm{~km}$ from all larger wind turbines $(\geq 500 \mathrm{~kW})$ with another turbine present within $500 \mathrm{~m}$, the sound levels have been calculated due to all turbines within $2.5 \mathrm{~km}$ of each address. This therefore includes the sound of smaller wind turbines $(<500 \mathrm{~kW})$.

In figure 3 all individually calculated immission levels according to the Dutch and the simplified model are plotted versus those of the ISO model. The Dutch and ISO models are highly correlated and yield almost identical results, as could be expected from the similarities between both models. The difference in results between the ISO and Dutch model are -0.8 to $1.4 \mathrm{~dB}(\mathrm{~A})$, the average difference is $0.3 \mathrm{~dB}$. The difference in results between the ISO and simplified model are -4.4 to $1.8 \mathrm{~dB}(\mathrm{~A})$, the average difference is $-0.8 \mathrm{~dB}$.
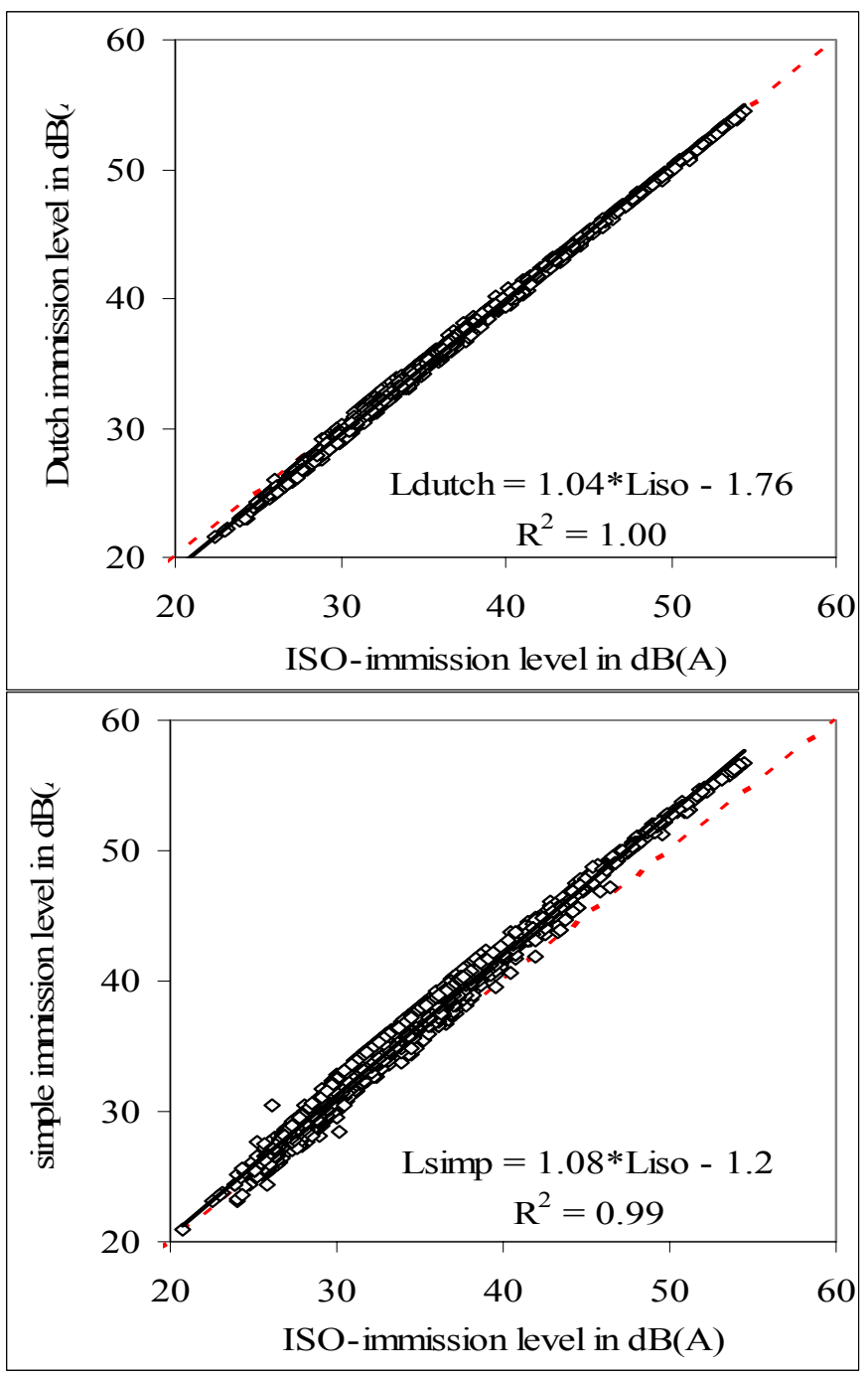

Figure 3: immission sound levels according to the Dutch (left) and simplified (right) models plotted versus the

ISO-9613 model; dotted line is best linear fit 
In figure 4 the sound immission level according to the ISO9613 model is plotted versus distance to the wind turbine closest to the immission point. There is a clear relationship between both with a slope of $-17.6 \mathrm{~dB}$ per decade. As expected, this is less steep than a single point source $(-20$ $\mathrm{dB}$ per decade). At distances of $100 \mathrm{~m}$ or more the variation at a specific distance is about $10 \mathrm{~dB}$. Just distance is thus a poor measure of the sound immission level.

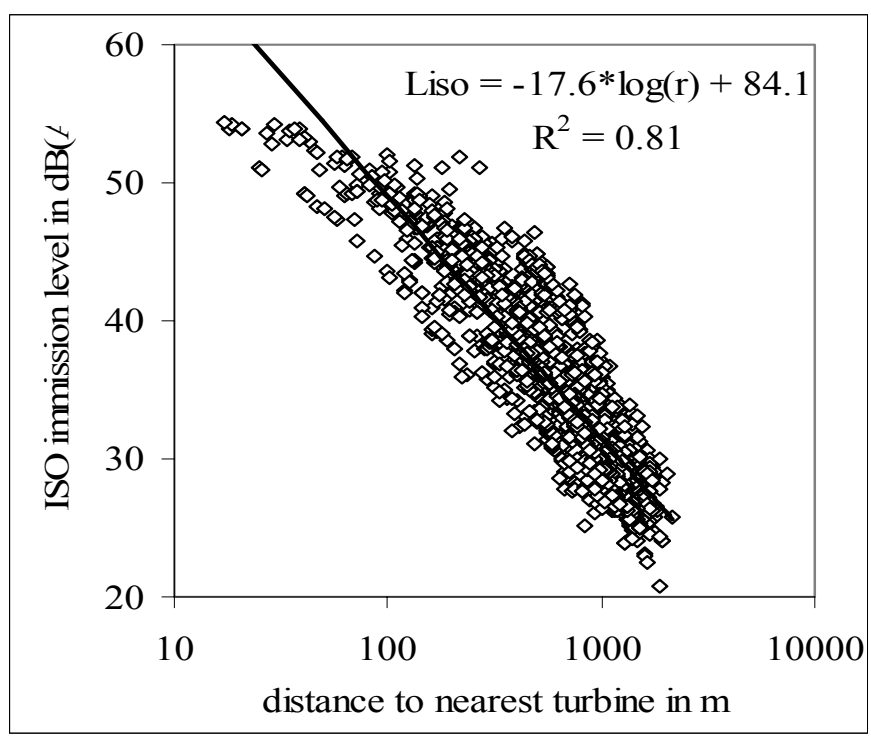

Figure 4: immission sound levels according to ISO-9613 due to all wind turbines plotted versus distance to nearest wind turbine

\section{$4 \quad$ Visual dose}

There is no generally accepted measure to determine the visual impact of a wind farm (or in fact the visual impact of other objects). Pedersen and Persson Waye [9] used the vertical angle spanned by a wind turbine as a measure of impact, defined as the angle between the horizontal at the receiver and the line between the receiver and the turbine hub. In hilly area, if a turbine is situated at an elevated position, this includes the angle between the horizontal and a line from the receiver to the base of the turbine. This implies that a $50 \mathrm{~m}$ high wind turbine on a $200 \mathrm{~m}$ hill at 500 $\mathrm{m}$ distance has the same impact as a $100 \mathrm{~m}$ high turbine at ground level at $250 \mathrm{~m}$ distance. It is not obvious this is plausible. However, in flat terrain elevation is irrelevant and the vertical angle only depends on distance and turbine height. When several wind turbines are visible, the vertical

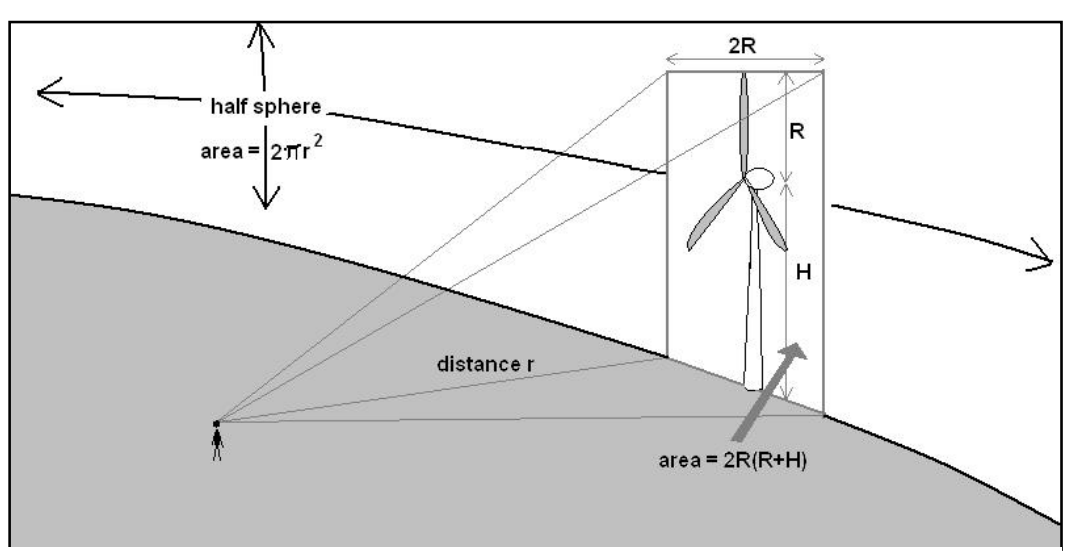

Figure 5: sketch of schematized turbine size relative to total field of view angle is the maximum value of the individual vertical angles.

For visual impact from a planning point of view "the two principal criteria determining significance (of effects) are the scale or magnitude of effect and the environmental sensitivity of the location or receptor" [10]. Visual impact of an object thus depends on the size of the object in the field of view and the appropriateness of the object in its environment, and thus depends on a quantity (relative size) and a quality (appropriateness). This quality depends on the contrast between the object and its environment (e.g. a highly technical object in a natural landscape, or a silver metal building between brown brick buildings) and the appreciation of the object in its environment (depending on purpose, material, perceived beauty, etc.), and must be determined from people's judgments. In fact, the response in this project may yield such a quality assessment.

The visual impact quantity is the size of an object in proportion to the field of view. It can be defined as the size of the object area normal to the line of sight, divided by the area of half a sphere with a radius equal to the distance between receiver and object. In the project the relative size is defined as the area $2 \mathrm{R}(\mathrm{R}+\mathrm{H})$ divided by the area $2 \pi \mathrm{r}^{2}$ of the half sphere with radius $r$, as illustrated in figure 5 . The quantifiable part of the visual impact is thus the fraction of the total field of view (= half sphere above the horizon) that is covered by a schematized turbine. This is equal to twice the space angle as defined in mathematics (twice because in mathematics the area is relative to the entire sphere). Replacing a wind turbine by a rectangle seems a very schematic approximation, but the rectangle area is highly correlated to the actual size of the rotor and/or rotor + mast because wind turbine diameter and hub height are highly correlated (best fit: diameter $=0.95 *$ hub height, correlation coefficient $=0.91$ ). The calculation is valid for a relative size $<<1$, because then the rectangle area projected on the curved sphere can be approximated with plane geometry. For bigger values the relative size will be overestimated by the calculation used. For several wind turbines the (total) relative size is the sum of the individual relative sizes.

In figure 6 both visual impact parameters for all respondents are plotted versus the distance between each receiver and the nearest wind turbine. Again the parameters are highly correlated.

Also the visual and aural impact parameters are highly correlated: the square of the correlation coefficient (coefficient of variation) of the sound immission level vs. relative size is 0.93 , vs. maximum angle it is 0.86 . 


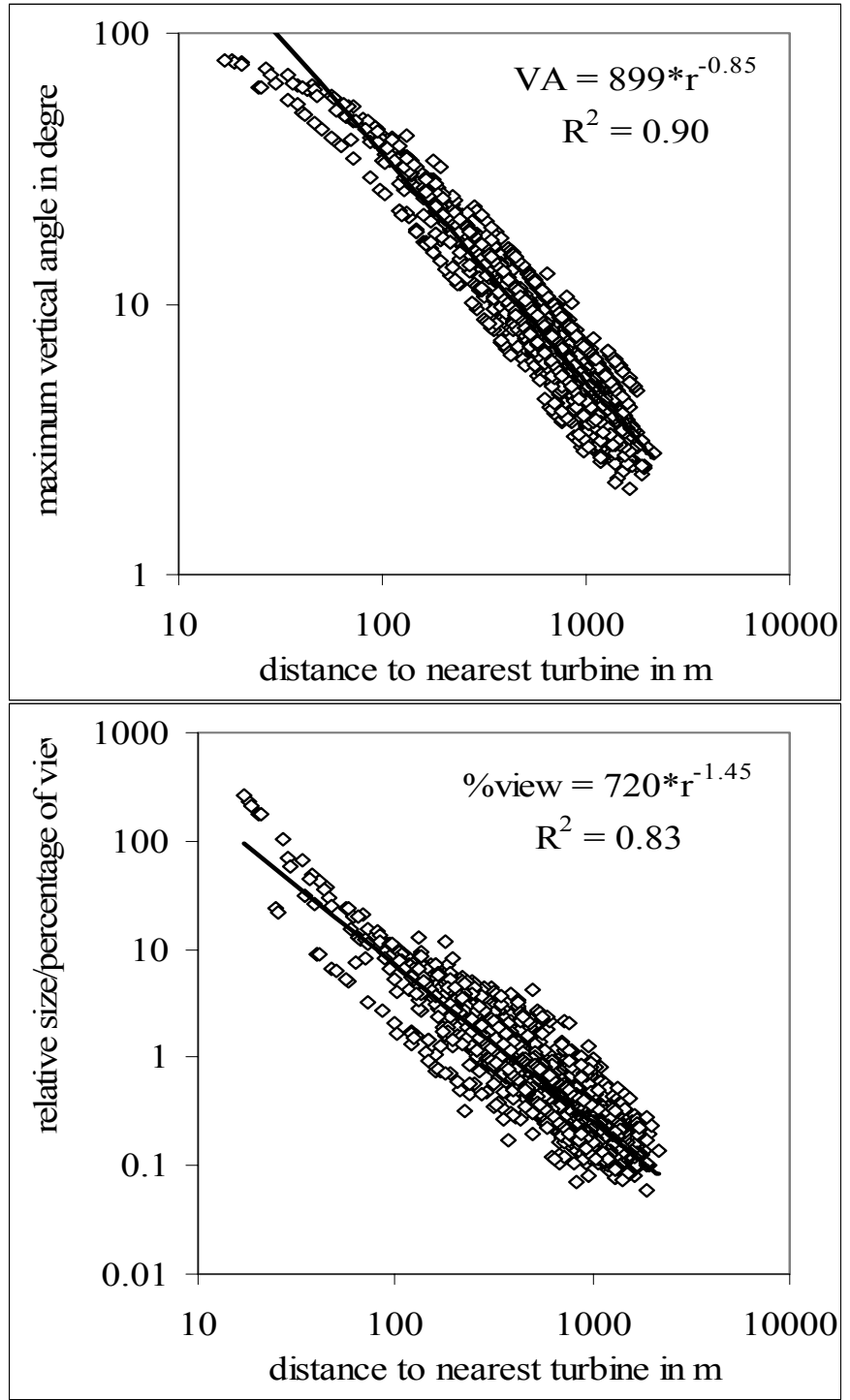

Figure 6: relation between visual impact parameters (above: maximum vertical angle, below: relative size/percentage of view) and distance to nearest wind turbine

\section{Conclusion}

We have explored the impact of modern wind turbines with a maximum electric power output of $500 \mathrm{~kW}$ or more, on residents living in the vicinity $(<2.5 \mathrm{~km})$ of present Dutch wind farms. At distances $>2.5 \mathrm{~km}$ the exposure is very low or nil.

To assess noise impact we have used the sound immission level at $8 \mathrm{~m} / \mathrm{s}$ in standard conditions, as was done in an earlier and similar survey. This was calculated at $4 \mathrm{~m}$ receiver height, assuming flat, absorbing ground between each wind turbine and receiver. The legally required Dutch and the international ISO propagation model yielded almost identical results; a simpler model gave results that were, on average, less than $1 \mathrm{~dB}$ higher and can thus serve to give a first approximation of the immission level of a wind farm. To assess visual impact we have used the angle between the horizontal and the highest blade tip as in the earlier survey, and have added a new dose parameter, the size of all wind turbines relative to the total field of view. However, all parameters are highly correlated, so they may be interchangeable as dose parameters.

\section{Acknowledgments}

We thank the European Union for acknowledging the importance of determining the impact of sustainable energy generation on residents by providing the funds for this project. We also thank Wind Service Holland for sharing their data on wind turbines in the Netherlands.

\section{References}

[1] Eja Pedersen, Jelte Bouma, Roel Bakker and Frits van den Berg: "Response to wind turbine noise in the Netherlands, proceedings Acoustics'08, Paris, June 29July 4 (2008)

[2] "Wind turnbine generator systems - Part 11: Acoustic noise measurements techniques", IEC standard 1640011:1998(E), Geneva (1998)

[3] Sondergaard, B: "Low Frequency Noise from Large Wind Turbines", proceedings 2nd International Conference on Wind Turbine Noise, Lyon (2007)

[4] "Handleiding meten en rekenen Industrielawaai" ("Manual for measuring and calculating industrial noise”), Ministerie van Volkshuisvesting, Ruimtelijke Ordening en Milieubeheer (VROM), den Haag (1999) (in Dutch)

[5] "ISO-9613.2: Attenuation of sound during propagation outdoors. Part 2: General method of calculation", International Organization for Standardization (1996)

[6] "The assessment and measurement of sound from wind generators”, New Zealand Standard NZS 6808 (1998)

[7] Pedersen, E and Persson Waye K: "Perception and annoyance due to wind turbine noise - a dose-response relationship", Journal of the Acoustical Society of America 116 (6), pp. 3460-3470 (2004)

[8] Frits van den Berg: "Criteria for wind farm noise: Lmax and Lden”, proceedings Acoustics'08, Paris, June 29-July 4 (2008)

[9] Pedersen, E and Persson Waye K: "Wind turbine noise, annoyance and self-reported health and wellbeing in different living environments", Occupational and Environmental Medicine, 64 (7), pp. 480-486 (2007)

[10] Landscape Institute and Institute of Environmental Management and Assessment (IEMA): “Guidelines for landscape and visual impact assessment”, London, Spon Press (2002) 